\title{
Caracterização morfofisiológica de isolados de rizóbios provenientes de solos ácidos da Amazônia Central
}

Os rizóbios, além de fixarem o nitrogênio atmosférico, possuem capacidade de solubilizar fosfatos insolúveis e produzir o ácido indolacético (AlA). Esse microrganismos representam alternativas viáveis para a produção agrícola sustentável na Amazônia. Este trabalho teve como objetivo realizar a caracterização morfofisiológica de isolados de rizóbios proveniente de solos ácidos da região de Manaus. Foram obtidos 22 isolados provenientes de raízes de leguminosas tropicais, sendo que $100 \%$ dos isolados mostraram-se tolerantes à acidez, e a maioria (86\%) cresceu satisfatoriamente em meio alcalino. Isso indica que os isolados são bastante versáteis com relação ao $\mathrm{pH}$ do solo. Todos os isolados foram sensíveis ao alumínio trocável ( $2 \mathrm{cmolc} \mathrm{dm}-3)$. Apenas nove isolados (41\%) foram capazes de solubilizar o fosfato de cálcio e nenhum solubilizou o fosfato de alumínio. Em relação à produção de AIA, 52\% foram capazes de sintetizar esse metabólito em meio com triptofano e tiveram a produção classificada entre baixa (38\%) e média (52\%). A partir da análise de cluster foi possível identificar 5 grupos distintos de rizóbios com $80 \%$ de grau de similaridade, evidenciando elevada diversidade morfofisiológica. Alguns isolados da mesma planta apresentam diferenças marcantes quanto às suas características.

Palavras-chave: Tolerância à acidez; Fosfatos insolúveis; Ácido indolacético; Fixação biológica do nitrogênio.

\section{Morphophysiological characterization of rhizobia isolates from acid soils of Central Amazonia}

\begin{abstract}
In addition to fixing atmospheric nitrogen, rhizobia has the ability to solubilize insoluble phosphates and produce indolacetic acid (AIA). These microorganisms represent viable alternatives for sustainable agricultural production in the Amazon. This work aimed to carry out the morphophysiological characterization of rhizobia isolates from acidic soils in the region of Manaus. 22 isolates were obtained from roots of tropical legumes, with $100 \%$ of the isolates being tolerant to acidity, and the majority (86\%) grew satisfactorily in an alkaline medium. This indicates that the isolates in terms of soil pH are quite versatile. All isolates were sensitive to exchangeable aluminum $(2 \mathrm{cmolc} . \mathrm{dm}-3)$. Only nine isolates $(41 \%)$ were able to solubilize calcium phosphate and none solubilized aluminum phosphate. Regarding the production of AIA, 52\% were able to synthesize this metabolite in medium with tryptophan and had the production classified between low (38\%) and medium (52\%). From the cluster analysis it was possible to identify 5 distinct groups of rhizobia with $80 \%$ similarity, showing high morphophysiological diversity. Some isolates from the same plant have marked differences in their characteristics.
\end{abstract}

Keywords: Acidity tolerance; Insoluble phosphates; Indolacetic acid; Biological nitrogen fixation.

Topic: Ciências do Solo

Reviewed anonymously in the process of blind peer.
Received: 03/04/2021

Approved: 26/04/2021
Luiz Carlos Costa de Souza (it)

Universidade do Estado do Amazonas, Brasil

http://lattes.cnpq.br/2336187088884800

http://orcid.org/0000-0002-4681-2114

luiz.costa.15@gmail.com

Francisco Adilson dos Santos Hara (iD

Universidade do Estado do Amazonas, Brasil

http://lattes.cnpq.br/5449496360182812

http://orcid.org/0000-0002-3215-953X

fhara@ufam.edu.br

Jhony Vendruscolo (iD

Universidade do Estado do Amazonas, Brasil

http://lattes.cnpq.br/4405434241565360

http://orcid.org/0000-0003-3043-0581

jhonyvendruscolo@gmail.com

\author{
Ariele Cristine Ferreira Inácio (iD \\ Universidade do Estado do Amazonas, Brasi \\ http://lattes.cnpq.br/2920432445769867 \\ http://orcid.org/0000-0002-7663-059X \\ arielec20@gmail.com \\ Milena Sousa Silva (iD \\ Universidade do Estado do Amazonas, Brasi \\ http://lattes.cnpq.br/6214290564310063 \\ http://orcid.org/0000-0002-7717-6915 \\ milenasousa231@gmail.com
}

Referencing this:

SOUZA, L. C. C.; HARA, F. A. S.; VENDRUSCOLO, J.; INÁCIO, A. C. F.; SILVA, M. S.. Caracterização morfofisiológica de isolados de rizóbios provenientes de solos ácidos da Amazônia Central. Revista Ibero Americana de Ciências Ambientais, v.12, n.4, p.21-34, 2021. DOI: http://doi.org/10.6008/CBPC2179-6858.2021.004.0003 


\section{INTRODUÇÃO}

A agricultura praticada por pequenos produtores na região Amazônica, é carente de recursos apropriados ao seu pleno desenvolvimento, uma vez que se dispõe de pouquíssima tecnologia, e segundo Homma et al. (2014) é baixa a contribuição de pequenos produtores no contexto da produção agrícola regional, que está perdendo a participação absoluta e relativa com o avanço de grandes monocultivos. A pequena produção rural local necessita de recursos para aumentar a sua produção e superar as dificuldades impostas pelas condições naturais, sociais, econômicas e ambientais da região. Entre os obstáculos de ordem natural está a baixa fertilidade dos solos da região, cuja maioria é composta pelos Latossolos e Argissolos (CAMPOS et al., 2012). Neste contexto, o nitrogênio e o fósforo são dois elementos essenciais para a planta e de difícil aplicação como fertilizantes pelos agricultores regionais, devido ao alto custo e dificuldades de transporte. No entanto, alguns microrganismos do solo, que se associam às raízes das plantas, podem tornálas menos dependentes de adubos químicos permitindo, assim, uma economia desses insumos e, ao mesmo tempo, maior produtividade dos solos.

A utilização de microrganismos que apresentem potencialidades para aplicações biotecnológicas, com o intuito de reduzir as dificuldades na produção de alimentos na região, diminuindo os custos na produção ao disponibilizar nutrientes essenciais às culturas agrícolas e ajudando a superar a problemática da acidez e baixa fertilidade dos solos, é uma alternativa para a Amazônia. A utilização de rizóbios na agricultura traz inúmeros benefícios, tornando possível reduções de custos e de impactos ambientais (GUALTER et al., 2011). Tendo-se o conhecimento das potencialidades biotecnológicas de microrganismos presentes nos solos da região poderá se fazer o uso dos mesmos para fins agrícolas e, consequentemente, melhorar a produtividade regional.

Dentre os microrganismos estão as bactérias nodulíferas dos gêneros Rhizobium, Sinorhizobium, Mesorhizobium, Azorhizobiume e Bradyrhizobium (genericamente designados por rizóbia), que fixam o nitrogênio atmosférico tornando-o disponível para as plantas e para o ecossistema (COSTA et al., 2013; JARAMILLO et al., 2013). A fixação biológica do nitrogênio atmosférico é importante na substituição da adubação nitrogenada em diversas partes do mundo (KUMAWAT et al., 2015; PADILLA et al., 2007; DEGEFU et al., 2018; OGEGA et al., 2018), bem como na Amazônia (HARA et al., 2019; CHAGAS JUNIOR et al., 2010).

Alguns trabalhos têm confirmado a versatilidade dos rizóbios quanto aos serviços ecológicos manifestados em sistemas agrícolas. Além de fixarem o nitrogênio atmosférico na associação com leguminosas, podem atuar como estimuladores de crescimentos de diversas culturas não leguminosas como o arroz, segundo Yanni et al. (2010); Osório Filho et al. (2014), o milho, o trigo e a canola, conforme Hahn et al. (2014). Vivendo endofiticamente, os rizóbios podem estimular o crescimento das plantas, devido à produção de substâncias hormonais (BISWAS et al., 2000), podem contribuir de forma indireta na nutrição de plantas através da solubilização de fosfatos insolúveis (MONTEIRO et al., 2018), e ainda possuem potencial de serem aproveitados em processo biotecnológicos como produtores de enzimas amilolíticas (FERNANDES et al., 2012). 
De acordo com Giongo et al. (2008), dentre os fatores que afetam a diversidade de rizóbios no solo estudos apontam que o $\mathrm{pH}$, solos argilosos e matéria orgânica são os principais limitantes, de modo que o pH é o principal fator que afeta a diversidade, sendo que solos argilosos com matéria orgânica exercem menor influência negativa na diversidade de tais microrganismos. Encontrar bactérias tolerantes a fatores estressantes pode ser um ponto chave para o sucesso de sistemas agroflorestais na Amazônia. Alguns trabalhos têm relatado a capacidade de isolados de rizóbios oriundos de solos da Amazônia em tolerar a acidez e altos níveis de alumínio trocável (HARA et al., 2005; HARA et al., 2007; CHAGAS JUNIOR et al., 2010). Essa tolerância das estirpes a fatores estressantes do solo como acidez e elevados teores de alumínio podem ser fundamental para suas sobrevivências em solos ácidos e intemperizados, como os de terra firme da Amazônia. Estirpes específicas, com a capacidade de superar tais condições, precisam ser selecionadas para uso em inoculantes (ANUAR et al., 1995; WANI et al., 1995), principalmente aquelas isoladas de solos onde o fator estressante predominou (ROSSUM et al., 1994).

A diversidade morfológica de rizóbios nativos isolados de nódulos radiculares de Leguminosas cultivadas em solos ácidos da Amazônia é de suma importância, sendo uma fonte de recursos genéticos para seleção de isolados adaptados às diversas condições. Os estudos taxonômicos através de ferramentas moleculares permitiram nos últimos anos mudanças na taxonomia dos rizóbios e identificação de novos grupos de bactérias capazes de induzir nódulos em leguminosas (CHEN et al., 2005). Entretanto, a avaliação das características culturais e morfológicas é o primeiro passo para a identificação de novos grupos taxonômicos de microrganismos e é muito útil em laboratórios que não têm acesso a tecnologias mais caras, pois essas avaliações são de baixo custo (JESUS et al., 2005).

Neste contexto, o referido trabalho objetivou avaliar as características morfológicas de isolados de rizóbios e o potencial dos mesmos para serem utilizados como bactérias estimuladoras de crescimento vegetal.

\section{MATERIAIS E MÉTODOS}

\section{Coleta dos nódulos e isolamento de rizóbios}

Os nódulos de leguminosas foram coletados em uma área da Fazenda Experimental da UFAM (Tabela 1), seguindo a metodologia proposta por Hungria et al. (1994). Inicialmente, foram selecionadas as plantas hospedeiras, em seguida realizou-se a remoção do solo próximo da rizosfera da planta (15 cm de raio e 30 $\mathrm{cm}$ de profundidade). Os nódulos presentes nos sistemas radiculares foram coletados e transferidos para tubos com sílica gel para desidratação e diminuição do metabolismo dos microrganismos.

O isolamento dos rizóbios também seguiu a metodologia proposta por Hungria et al. (1994). Os nódulos coletados foram mergulhados em placas de petri contendo álcool a 90-95\% por um período de 5 a 10 segundos. Em seguida, os nódulos foram esterilizados com solução de hipoclorito de sódio (3\%). Imediatamente, os nódulos foram lavados em água destilada esterilizada. Após a lavagem, os nódulos foram acondicionados em recipientes de vidros estéreis, e depois realizou-se o esmagamento dos nódulos nos 
vidros com bastão esterilizado. O material resultado do esmagamento dos nódulos foi riscado em meio YM (Yeast-Manitol). O pH do meio foi ajustado para 6,5 com Hidróxido de sódio (10\%). Foi adicionado o corante

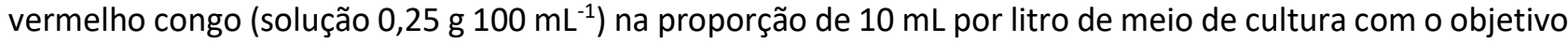
de identificar os possíveis contaminantes, pois os mesmos absorvem a cor vermelho, enquanto as colônias de rizóbio não absorvem ou absorvem muito pouco.

\section{Caracterização fenotípica dos isolados}

A caracterização fenotípica dos isolados foi feita de acordo com a metodologia proposta por Chagas Junior et al. (2010). Os isolados foram repicados em meio de cultura sólido contendo o corante azul de bromotimol $\left(0,5 \mathrm{~g} \mathrm{~L}^{-1}\right)$ na proporção de $5 \mathrm{ml}$ por litro do meio de cultura, para verificar a mudança da coloração do meio para amarelo quando acidificar ou para azul mediante alcalinização.

As características avaliadas foram: crescimento ( $\leq 3$ dias ou $>3$ dias); alteração do $\mathrm{pH}$ do meio (ácido, neutro ou alcalino); elevação da colônia (plana, lenticular convexa, pulvinada, umbonada ou umbilicada); forma da borda (inteira, ondulada, lobada, denteada ou filamentosa); superfície da colônia (lisa, rugosa ou papilada); consistência (seca, aquosa, gomosa, viscosa ou butírica); detalhes ópticos (translúcida ou opaca).

\section{Avaliação das características fisiológicas}

\section{Tolerância a acidez e a alta concentração de alumínio trocável}

Os isolados purificados em placas de Petri em meio YMA $(\mathrm{pH} 6,5)$ foram submetidos a acidez e alta concentração de alumínio trocável. Os tratamentos utilizados foram meios YMA com pH 4,5; pH 4,5 + 2,0 $\mathrm{cmol}_{\mathrm{C}} \mathrm{Al} \mathrm{L}^{-1}$ e pH 6,5, sendo que o alumínio foi aplicado na forma de $\mathrm{AlCl}_{3}$. O experimento foi instalado em três repetições por placa de petri. Com o objetivo de verificar a alteração do pH do meio pelas bactérias, em função da alteração da cor do meio, foi acrescentado o corante indicador bromocresol verde nos meios com $\mathrm{pH}$ 4,5 e pH 4,5 + Al e, no meio com pH 6,5, foi acrescentado o azul de bromotimol. Esses corantes permitiram verificar a alteração de $\mathrm{pH}$ pelos isolados. Os isolados foram mantidos a temperatura ambiente.



Figura 1: Ilustração do método de riscagem proposto por Oliveira et al. (1999). A figura demonstra apenas uma repetição.

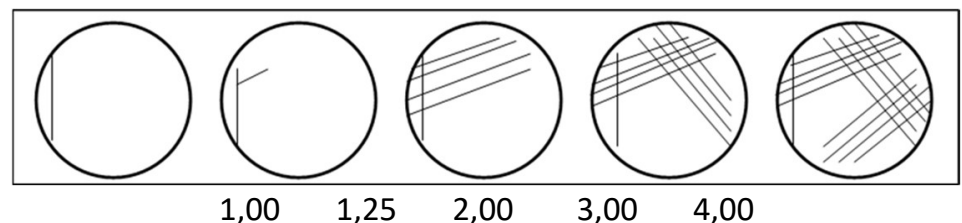

Figura 2: Valores de crescimento para os isolados de rizóbio nos respectivos tratamentos em placas de Petri com meio YMA (OLIVEIRA et al., 1999). 
Para a avaliação foi utilizado o método de riscagem proposto por Oliveira et al. (1999). As avaliações foram realizadas a cada três dias, durante um período de 18 dias. De acordo com o crescimento celular nas respectivas zonas (Figura 1), foram adotados valores de crescimento para cada estirpe variando de 1 a 4 (Figura 2), podendo ter valores intermediários entre esses extremos. Este método permite ainda, selecionar isolados e classificá-los de acordo com o grau de tolerância, no qual a média de crescimento das placas entre os valores de 1,00 - 2,00 classifica o isolado como sensível; entre 2,06 - 3,00 mediano; e entre 3,06 - 4,00 tolerante.

\section{Avaliação da capacidade de solubilização de fosfato}

Foi utilizado um meio específico para solubilizadora de fosfato de cálcio, contendo $10 \mathrm{~g}$ de glucose, $2 \mathrm{~g}$ de extrato de levedura e $18 \mathrm{~g}$ de ágar, conforme Sylvester-Bradley et al. (1982). Foi acrescentada uma solução $\mathrm{A}$ contendo $5 \mathrm{~g}$ de $\mathrm{K}_{2} \mathrm{HPO}_{4}$ e $50 \mathrm{~mL}$ de água, e uma solução $\mathrm{B}$ contendo $10 \mathrm{~g}$ de $\mathrm{CaCl}_{2}$ em $100 \mathrm{~mL}$ de água, para que ocorra a formação do fosfato de cálcio precipitado. Em seguida, calibrou-se o pH para 6,5. Foi preparado um segundo meio para a verificar a solubilização de fosfato de alumínio, contendo $10 \mathrm{~g}$ de manitol, $2 \mathrm{~g}$ de extrato de levedura, $6 \mathrm{~g}$ de $\mathrm{K}_{2} \mathrm{HPO}_{4}$ e $18 \mathrm{~g}$ de ágar, sendo que foi acrescentada uma solução contendo 5,34 de $\mathrm{AlCl}_{3}$, para formar o precipitado de fosfato de alumínio. $\mathrm{O} \mathrm{pH}$ do meio foi calibrado para 4,5.

Os isolados de rizóbio crescidos em meio YMA $(\mathrm{pH}$ 6,5) foram repicados para os meios de solubilização de fosfato, estabelecendo-se cinco colônias por placa, com duas placas por estirpe. A avaliação ocorreu durante um período de 15 dias, cujas medidas do diâmetro $(\phi)$ dos halos de solubilização e das colônias foram mensurados a cada três dias. A partir dessas medidas foram obtidos os Índices de Solubilização (IS) para cada isolado através da fórmula: IS = $\phi$ Halo $(\mathrm{mm}) / \phi$ Colônia $(\mathrm{mm})$ (BERRAQUERO et al., 1976). Baseado nos índices de solubilização, as bactérias foram classificadas como isolados com baixa (IS <2), média $(2 \leq$ IS < 4) e alta (IS > 4) capacidade de solubilização. De acordo com o início da solubilização, as bactérias foram classificadas ainda como "precoces", cujo início da solubilização ocorrerá a partir do terceiro dia, "tardia", com início da solubilização a partir do sexto dia, e "não solubilizadoras", aquelas que não apresentaram solubilização visível até o décimo quinto dia de avaliação.

\section{Avaliação da capacidade de produzir AIA}

Para os testes de síntese de AIA pelos isolados de rizóbios foram utilizadas colônias de 2-3 mm de diâmetro. As colônias dos isolados de rizóbio purificadas em placas de Petri foram transferidas para Erlenmeyers de $150 \mathrm{~mL}$, contendo $25 \mathrm{~mL}$ de meio de cultura YM (meio líquido) na ausência e presença de triptofano (0 e $150 \mathrm{mg} \mathrm{L}^{-1}$ ). As amostras ficaram durante quatro dias em crescimento sobre um agitador rotatório na velocidade de $100 \mathrm{rpm}$ a $26 \pm 2{ }^{\circ} \mathrm{C}$. Após este período a biomassa bacteriana foi separada por centrifugação a $12.000 \mathrm{rpm}$ por $15 \mathrm{~min}$. O sobrenadante foi utilizado para as análises colorimétricas de AIA. Foram utilizadas uma parte do reagente de Salkowski $\left[\left(\mathrm{FeCl}_{3} 0,5 \mathrm{M}+\mathrm{HClO}_{4}(35 \%)\right]\right.$ e duas partes do sobrenadante bacteriano. Após a comprovação qualitativa de AIA no sobrenadante, com o aparecimento da coloração rosa após 25 min de reação a $26 \pm 2{ }^{\circ} \mathrm{C}$, o AIA foi quantificado em espectrofotômetro a $530 \mathrm{~nm}$. 
As concentrações $\left(\mu \mathrm{g} \mathrm{mL}^{-1}\right.$ ) foram calculadas a partir de uma curva padrão construída a partir de concentrações conhecidas da forma sintética do hormônio ( 0 a $100 \mu \mathrm{g} \mathrm{mL}^{-1}$ ), cujas leituras foram adotadas como base para calcular a concentração de AIA nas amostras. A produção do triptofano foi avaliada conforme a metodologia proposta por Chagas Junior et al. (2010), usando-se três níveis de produção: $<100 \mu \mathrm{gL}^{-1}$, > $100<500 \mu \mathrm{gL}^{-1}$, e $>500 \mu \mathrm{gL}^{-1}$.

\section{RESULTADOS E DISCUSSÃO}

Foram obtidos vinte e dois isolados de rizóbios das raízes de plantas leguminosas, os quais foram identificados com suas respectivas espécies de plantas de origem (Tabela 1). Cada isolado foi identificado a partir de um nódulo de cada planta. Os isolados foram purificados e armazenados em tubos de ensaio contendo YMA a temperatura ambiente.

Tabela 1: Isolados de rizóbios com suas respectivas plantas hospedeiras.

\begin{tabular}{|c|c|c|}
\hline \multicolumn{2}{|l|}{ Espécie vegetal } & \multirow{2}{*}{ Isolado/código de identificação } \\
\hline Nome popular - Planta & Nome científico & \\
\hline \multirow{3}{*}{ Puerária - 1} & & FCAN01a \\
\hline & Pueraria phaseoloides & FCANO1b \\
\hline & & FCAN01c \\
\hline \multirow{3}{*}{ Puerária - 2} & & FCAN02a \\
\hline & Pueraria phaseoloides & FCAN02b \\
\hline & & FCANO2c \\
\hline \multirow{3}{*}{ Mucuna Preta - 3} & & FCANO3a \\
\hline & Stizolobium aterrimum Piper \& Tracy & FCAN03b \\
\hline & & FCANO3C \\
\hline \multirow{3}{*}{ Mucuna Preta - 4} & & FCAN04a \\
\hline & Stizolobium aterrimum Piper \& Tracy & FCANO4b \\
\hline & & FCANO4c \\
\hline \multirow[t]{2}{*}{ Mucuna Preta - 5} & Stizolobium aterrimum Piper \& Tracy & FCAN05a \\
\hline & . & FCAN06a \\
\hline \multirow[t]{2}{*}{ Feijão Guandu - 6} & Cajanus cajan (L.) Millsp. & FCAN06b \\
\hline & & FCAN06c \\
\hline \multirow{3}{*}{ Feijão Guandu - 7} & & FCAN07a \\
\hline & Cajanus cajan (L.) Millsp. & FCAN07b \\
\hline & & FCAN07c \\
\hline \multirow{3}{*}{ Feijão de Porco - 8} & & FCAN08a \\
\hline & Canavalia ensiformis (L.) DC & FCAN08b \\
\hline & & FCAN08c \\
\hline
\end{tabular}

*As letras a, b e c significam nódulos diferentes da mesma planta/espécie correspondente.

\section{Caracterização Fenotípica}

Quando se analisou as características fenotípicas dentro de cada espécie, foi possível observar diferenças morfológicas das colônias entre isolados obtidos de uma mesma planta da mesma espécie, com exceção daqueles oriundos dos nódulos das plantas Feijão Guandu-7 e do Feijão de Porco-8 (Tabela 1 e 2). Foram observadas semelhanças morfológicas entre isolados obtidos de espécies diferentes, formando basicamente três grupos de isolados mais expressivos, sendo o primeiro formado por isolados obtidos da Mucuna Preta-5, Feijão Guandu-6, Feijão Guandu-7 e Feijão de Porco-8, um segundo formado pelos isolados obtidos da Puerária-2, Mucuna Preta-3, Mucuna Preta-4 e Feijão Guandu-6 e o terceiro formado pelos isolados obtidos da Puerária-1, Mucuna Preta-4 e Feijão Guandu-6 (Tabela 2).

Todos os isolados apresentaram crescimento rápido, isto é, crescimento entre o primeiro e o terceiro 
dia de incubação, e foram classificados como acidificadores do meio (Tabela 2). 0 crescimento rápido é uma estratégia de sobrevivência em ambientes estressantes como os solos ácidos ou de baixa umidade. A modificação de $\mathrm{pH}$ do meio de cultura é uma característica frequente dos gêneros Mesorhizobium, Rhizobium e Sinorhizobium (LIMA et al., 2012). Segundo Cunha et al. (2018), essa alteração de pH promovida pelo rizóbio de crescimento rápido no meio de cultura pode ser em decorrência do uso preferencial de açúcares, com consequente excreção de ácidos orgânicos. A presença de isolados bacterianos de crescimento rápido e hábeis a acidificar o meio é comum em solos da região Amazônica, conforme os resultados obtidos por Cassetari (2010) e Inácio et al. (2020). Esse processo de seleção de isolados tolerantes a acidez é importante para promover a sobrevivência de populações mais eficientes e específicas, e a obtenção de genótipos mais adaptados aos tipos de solo e tolerantes aos diferentes estresses ambientais (EHRHARDT-BROCARDO et al., 2015). Tendo em vista o conhecimento e a necessidade de estudos da diversidade de espécies de rizóbios presentes nos solos ácidos da Amazônia, os dados obtidos neste trabalho podem auxiliar em estudos sobre a diversidade de microrganismos presentes nos solos da região, seus comportamentos fisiológicos e, posteriormente, sua identificação, sendo possível comprovar se os caracteres distintos observados se dão pelo fato de pertencerem a grupos taxonômicos diferentes.

Tabela 2: Características morfológicas dos isolados de rizóbios.

\begin{tabular}{|c|c|c|c|c|c|c|c|c|}
\hline Isolados & Crescimento & $\begin{array}{l}\text { Alteração } \\
\text { do } \mathrm{pH}\end{array}$ & Consistência & $\begin{array}{l}\text { Detalhes } \\
\text { ópticos }\end{array}$ & Elevação & Borda & Superfície & Forma \\
\hline $\begin{array}{l}\text { FCAN01a } \\
\text { FCAN01b } \\
\text { FCAN01c }\end{array}$ & $\begin{array}{l}\text { 3o dia } \\
\text { 3o dia } \\
\text { 10 dia }\end{array}$ & $\begin{array}{l}\text { Acidificou } \\
\text { Acidificou } \\
\text { Acidificou }\end{array}$ & $\begin{array}{l}\text { Úmida } \\
\text { Úmida } \\
\text { Úmida }\end{array}$ & $\begin{array}{l}\text { Opaca } \\
\text { Opaca } \\
\text { Translúcida }\end{array}$ & $\begin{array}{l}\text { Lenticular } \\
\text { Lenticular } \\
\text { Convexa }\end{array}$ & $\begin{array}{l}\text { Inteira } \\
\text { Ondulada } \\
\text { Inteira }\end{array}$ & $\begin{array}{l}\text { Lisa } \\
\text { Lisa } \\
\text { Lisa }\end{array}$ & $\begin{array}{l}\text { Circular } \\
\text { Irregular } \\
\text { Circular }\end{array}$ \\
\hline $\begin{array}{l}\text { FCAN02b } \\
\text { FCAN02c }\end{array}$ & $\begin{array}{l}\text { 10 dia } \\
\text { 10 dia }\end{array}$ & $\begin{array}{l}\text { Acidificou } \\
\text { Acidificou }\end{array}$ & $\begin{array}{l}\text { Úmida } \\
\text { Úmida }\end{array}$ & $\begin{array}{l}\text { Translúcida } \\
\text { Translúcida }\end{array}$ & $\begin{array}{l}\text { Lenticular } \\
\text { Lenticular }\end{array}$ & $\begin{array}{l}\text { Inteira } \\
\text { Ondulada }\end{array}$ & $\begin{array}{l}\text { Lisa } \\
\text { Lisa }\end{array}$ & $\begin{array}{l}\text { Circular } \\
\text { Irregular }\end{array}$ \\
\hline $\begin{array}{l}\text { FCAN03a } \\
\text { FCAN03b } \\
\text { FCAN03c }\end{array}$ & $\begin{array}{l}\text { 20 dia } \\
\text { 20 dia } \\
\text { 20 dia }\end{array}$ & $\begin{array}{l}\text { Acidificou } \\
\text { Acidificou } \\
\text { Acidificou }\end{array}$ & $\begin{array}{l}\text { Úmida } \\
\text { Úmida } \\
\text { Úmida }\end{array}$ & $\begin{array}{l}\text { Translúcida } \\
\text { Translúcida } \\
\text { Translúcida }\end{array}$ & $\begin{array}{l}\text { Lenticular } \\
\text { Lenticular } \\
\text { Lenticular }\end{array}$ & $\begin{array}{l}\text { Inteira } \\
\text { Inteira } \\
\text { Inteira }\end{array}$ & $\begin{array}{l}\text { Lisa } \\
\text { Lisa } \\
\text { Lisa }\end{array}$ & $\begin{array}{l}\text { Circular } \\
\text { Irregular } \\
\text { Circular }\end{array}$ \\
\hline $\begin{array}{l}\text { FCAN04a } \\
\text { FCAN04b } \\
\text { FCAN04c }\end{array}$ & $\begin{array}{l}\text { 20 dia } \\
\text { 20 dia } \\
\text { 20 dia }\end{array}$ & $\begin{array}{l}\text { Acidificou } \\
\text { Acidificou } \\
\text { Acidificou }\end{array}$ & $\begin{array}{l}\text { Úmida } \\
\text { Úmida } \\
\text { Seca }\end{array}$ & $\begin{array}{l}\text { Opaca } \\
\text { Translúcida } \\
\text { Opaca }\end{array}$ & $\begin{array}{l}\text { Lenticular } \\
\text { Lenticular } \\
\text { Convexa }\end{array}$ & $\begin{array}{l}\text { Inteira } \\
\text { Inteira } \\
\text { Inteira } \\
\end{array}$ & $\begin{array}{l}\text { Lisa } \\
\text { Lisa } \\
\text { Lisa }\end{array}$ & $\begin{array}{l}\text { Circular } \\
\text { Circular } \\
\text { Circular }\end{array}$ \\
\hline FCAN05a & 2o dia & Acidificou & Úmida & Translúcida & Convexa & Inteira & Lisa & Circular \\
\hline $\begin{array}{l}\text { FCAN06a } \\
\text { FCAN06b } \\
\text { FCAN06c }\end{array}$ & $\begin{array}{l}\text { 20 dia } \\
\text { 20 dia } \\
\text { 20 dia }\end{array}$ & $\begin{array}{l}\text { Acidificou } \\
\text { Acidificou } \\
\text { Acidificou }\end{array}$ & $\begin{array}{l}\text { Úmida } \\
\text { Úmida } \\
\text { Úmida }\end{array}$ & $\begin{array}{l}\text { Opaca } \\
\text { Translúcida } \\
\text { Translúcida }\end{array}$ & $\begin{array}{l}\text { Lenticular } \\
\text { Lenticular } \\
\text { Convexa }\end{array}$ & $\begin{array}{l}\text { Inteira } \\
\text { Inteira } \\
\text { Inteira } \\
\end{array}$ & $\begin{array}{l}\text { Lisa } \\
\text { Lisa } \\
\text { Lisa }\end{array}$ & $\begin{array}{l}\text { Circular } \\
\text { Circular } \\
\text { Circular }\end{array}$ \\
\hline $\begin{array}{l}\text { FCAN07a } \\
\text { FCAN07b } \\
\text { FCAN07c }\end{array}$ & $\begin{array}{l}\text { 20 dia } \\
\text { 20 dia } \\
\text { 20 dia }\end{array}$ & $\begin{array}{l}\text { Acidificou } \\
\text { Acidificou } \\
\text { Acidificou }\end{array}$ & $\begin{array}{l}\text { Úmida } \\
\text { Úmida } \\
\text { Úmida }\end{array}$ & $\begin{array}{l}\text { Translúcida } \\
\text { Translúcida } \\
\text { Translúcida }\end{array}$ & $\begin{array}{l}\text { Convexa } \\
\text { Convexa } \\
\text { Convexa }\end{array}$ & $\begin{array}{l}\text { Inteira } \\
\text { Inteira } \\
\text { Inteira }\end{array}$ & $\begin{array}{l}\text { Lisa } \\
\text { Lisa } \\
\text { Lisa }\end{array}$ & $\begin{array}{l}\text { Circular } \\
\text { Circular } \\
\text { Circular }\end{array}$ \\
\hline $\begin{array}{l}\text { FCAN08a } \\
\text { FCAN08b } \\
\text { FCAN08c }\end{array}$ & $\begin{array}{l}\text { 20 dia } \\
\text { 20 dia } \\
\text { 20 dia }\end{array}$ & $\begin{array}{l}\text { Acidificou } \\
\text { Acidificou } \\
\text { Acidificou }\end{array}$ & $\begin{array}{l}\text { Úmida } \\
\text { Úmida } \\
\text { Úmida }\end{array}$ & $\begin{array}{l}\text { Translúcida } \\
\text { Translúcida } \\
\text { Translúcida }\end{array}$ & $\begin{array}{l}\text { Convexa } \\
\text { Convexa } \\
\text { Convexa }\end{array}$ & $\begin{array}{l}\text { Inteira } \\
\text { Inteira } \\
\text { Inteira } \\
\end{array}$ & $\begin{array}{l}\text { Lisa } \\
\text { Lisa } \\
\text { Lisa }\end{array}$ & $\begin{array}{l}\text { Circular } \\
\text { Circular } \\
\text { Circular }\end{array}$ \\
\hline \multicolumn{9}{|c|}{ Proporção das características morfológicas (\%) } \\
\hline & $\begin{array}{ll}10 & \text { dia } \\
(14,29 \%) & \\
20 & \text { dia } \\
(76,19 \%) & \\
3^{\circ} & \text { dia } \\
(9,52 \%) & \\
\end{array}$ & $\begin{array}{l}\text { Acidificou } \\
(100 \%)\end{array}$ & $\begin{array}{l}\text { Úmida } \\
(95,24 \%) \\
\text { Seca }(4,76 \%)\end{array}$ & $\begin{array}{l}\text { Opaca } \\
(23,81 \%) \\
\text { Translúcida } \\
(76,19 \%)\end{array}$ & $\begin{array}{l}\text { Lenticular } \\
(52,38 \%) \\
\text { Convexa } \\
(47,62 \%)\end{array}$ & $\begin{array}{l}\text { Inteira } \\
(90,48 \%) \\
\text { Ondulada } \\
(9,52 \%)\end{array}$ & $\begin{array}{l}\text { Lisa } \\
(100 \%)\end{array}$ & $\begin{array}{l}\text { Circular } \\
(85,71 \%) \\
\text { Irregular } \\
(14,29 \%)\end{array}$ \\
\hline
\end{tabular}

Tolerância à acidez e a alta concentração de alumínio trocável

Todos os isolados de rizóbios manifestaram comportamento de tolerância à acidez, no entanto, nenhum isolado apresentou tolerância aos fatores acidez e alumínio conjugados (Tabela 3). Stefan et al. 
(2018), Feitoza et al. (2015) e Cunha et al. (2018) também observaram predominância de isolados de rizóbios tolerantes à acidez em detrimento de isolados tolerantes à acidez + alumínio. Tal fenômeno pode ser explicado pelo fato de que a acidez afeta apenas a solubilidade de íons presente no meio, enquanto o alumínio afeta diretamente o metabolismo dos organismos. Além disso, a acidificação do meio de cultura pode ter potencializado o efeito do alumínio, pois a taxa de dissolução desse íon é dependente do pH, ou seja, os íons de Al tendem a aumentar com a diminuição do pH do solo, de acordo com Violante et al. (2010), predominando a forma trivalente que é altamente tóxica aos microrganismos (ZIOŁA-FRANKOWSKA e FRANKOWSKI, 2018). Ao se comparar os resultados deste trabalho com outros realizados com isolados provenientes de solos da Amazônia, como os de Hara et al. (2004), onde se obtiveram apenas $25 \%$ de isolados tolerantes à acidez, Hara et al. (2005) com 57 \% de isolados classificados como tolerantes e, Hara et al. (2007) com $92 \%$ de isolados tolerantes a acidez, verifica-se que este trabalho alcançou índices superiores e os resultados obtidos foram satisfatórios, quanto a este fator avaliado.

Segundo Kopittke et al. (2015), os microssimbiontes, são afetados de forma negativa pelo alumínio, embora em menor proporção que as leguminosas hospedeiras, e de acordo com Ferreira et al. (2012) a depressão do crescimento celular causada pelo alumínio é decorrente da alteração do metabolismo celular, e segundo Jaiswal et al. (2018) pode afetar a função do nitrato redutase, nitrito redutase e nitrogenase, e a absorção de hidrogenase em rizóbios de crescimento lento e rápido. O alumínio pode causar interferência no metabolismo do fosfato das células bacterianas e com isso diminuir o crescimento celular (FLIS et al., 1993). De acordo com os mesmos autores há evidências de que o alumínio, após entrar na célula, se liga às cargas negativas do grupo fosfato da dupla hélice do DNA, aumentando sua estabilidade e prevenindo sua replicação. Desse modo, esses fatores podem ter sido determinantes para que os isolados não tenham apresentado tolerância ao meio contendo tal elemento.

Tabela 3: Crescimento em meio de cultivo com pH 4,5, pH 6,5 e pH 4,5 + Al (Oliveira et al., 1999) dos isolados de rizóbios.

\begin{tabular}{|c|c|c|c|c|c|c|c|c|c|c|c|c|}
\hline \multirow[t]{4}{*}{ Isolados } & \multicolumn{12}{|c|}{ Dias de avaliação } \\
\hline & \multicolumn{3}{|l|}{$3^{\circ}$} & \multicolumn{3}{|l|}{$6^{\circ}$} & \multicolumn{3}{|l|}{$12^{\circ}$} & \multicolumn{3}{|l|}{$15^{\circ}$} \\
\hline & \multicolumn{12}{|l|}{$\mathrm{pH}$} \\
\hline & 4,5 & 6,5 & $\mathrm{pH} 4,5+\mathrm{Al}$ & 4,5 & 6,5 & $\mathrm{pH} 4,5+\mathrm{Al}$ & 4,5 & 6,5 & $\mathrm{pH} 4,5+\mathrm{Al}$ & 4,5 & 6,5 & $\mathrm{pH} 4,5+\mathrm{Al}$ \\
\hline FCAN01a & 4,00 & 3,83 & 1,00 & 4,00 & 4,00 & 1,00 & 4,00 & 4,00 & 1,00 & 4,00 & 4,00 & 1,00 \\
\hline FCAN01b & 4,00 & 4,00 & 0,00 & 4,00 & 4,00 & 0,00 & 4,00 & 4,00 & 0,00 & 4,00 & 4,00 & 0,00 \\
\hline FCAN01c & 2,92 & 2,83 & 0,00 & 2,92 & 3,08 & 0,00 & 3,08 & 3,17 & 0,00 & 3,25 & 3,17 & 0,00 \\
\hline FCAN02b & 4,00 & 4,00 & 1,00 & 4,00 & 4,00 & 1,00 & 4,00 & 4,00 & 1,00 & 4,00 & 4,00 & 1,00 \\
\hline FCANO2C & 4,00 & 3,08 & 1,00 & 4,00 & 3,33 & 1,00 & 4,00 & 3,50 & 1,00 & 4,00 & 3,50 & 1,00 \\
\hline FCAN03a & 3,67 & 3,33 & 1,00 & 3,67 & 3,67 & 1,00 & 3,92 & 3,67 & 1,00 & 3,92 & 3,67 & 1,00 \\
\hline FCANO3b & 3,17 & 3,83 & 1,00 & 3,25 & 3,83 & 1,00 & 3,33 & 3,83 & 0,00 & 3,42 & 3,83 & 0,00 \\
\hline FCANO3c & 3,50 & 3,17 & 0,00 & 3,75 & 3,17 & 0,00 & 3,92 & 3,25 & 0,00 & 3,92 & 3,25 & 0,00 \\
\hline FCANO4a & 3,67 & 2,50 & 1,00 & 4,00 & 2,83 & 1,00 & 4,00 & 2,92 & 1,00 & 4,00 & 3,00 & 1,00 \\
\hline FCANO4b & 3,00 & 2,50 & 0,00 & 3,25 & 2,67 & 0,00 & 3,33 & 2,75 & 0,00 & 3,50 & 2,83 & 0,00 \\
\hline FCANO4c & 4,00 & 1,67 & 0,00 & 4,00 & 2,0 & 0,00 & 4,00 & 2,0 & 0,00 & 4,00 & 2,00 & 0,00 \\
\hline FCAN05a & 4,00 & 4,00 & 1,00 & 4,00 & 4,00 & 1,00 & 4,00 & 4,00 & 0,00 & 4,00 & 4,00 & 0,00 \\
\hline FCAN06a & 1,00 & 2,17 & 0,00 & 1,75 & 2,75 & 0,00 & 3,0 & 3,17 & 0,0 & 3,08 & 3,17 & 0,00 \\
\hline FCAN06b & 3,50 & 4,00 & 1,00 & 3,92 & 4,00 & 1,00 & 4,00 & 4,00 & 1,00 & 4,00 & 4,00 & 1,00 \\
\hline FCAN06c & 3,25 & 3,5 & 1,00 & 3,67 & 4,00 & 1,00 & 4,00 & 4,00 & 1,00 & 4,00 & 4,00 & 1,00 \\
\hline FCAN07a & 3,30 & 3,7 & 0,00 & 3,58 & 4,00 & 0,00 & 3,58 & 4,00 & 1,00 & 3,67 & 4,00 & 1,00 \\
\hline FCAN07b & 3,50 & 3,7 & 1,00 & 3,92 & 4,00 & 1,00 & 4,00 & 4,00 & 1,00 & 4,00 & 4,00 & 1,00 \\
\hline FCAN07c & 3,30 & 4,00 & 1,00 & 3,58 & 4,00 & 1,00 & 3,58 & 4,00 & 1,00 & 3,83 & 4,00 & 1,00 \\
\hline FCAN08a & 3,70 & 4,00 & 1,00 & 3,92 & 4,00 & 1,00 & 4,00 & 4,00 & 1,00 & 4,00 & 4,00 & 1,00 \\
\hline FCAN08b & 3,83 & 4,00 & 1,00 & 3,92 & 4,00 & 1,00 & 4,00 & 4,00 & 1,00 & 4,00 & 4,00 & 1,00 \\
\hline FCAN08c & 4,00 & 4,00 & 0,00 & 4,00 & 4,00 & 0,00 & 4,00 & 4,00 & 0,0 & 4,00 & 4,00 & 0,00 \\
\hline
\end{tabular}


Os crescimentos dos isolados foram semelhantes no primeiro dia de avaliação no $\mathrm{pH}$ ácido e em $\mathrm{pH}$ alcalino, pois em ambos já no primeiro dia de avaliação $86 \%$ dos isolados foram classificados como tolerantes (Tabela 3). Enquanto que ao final das análises no meio ácido $100 \%$ dos isolados foram classificados como tolerantes, e no meio alcalino $86 \%$, ou seja, os resultados da primeira análise para o meio alcalino se mantiveram até o último dia de avaliação. Silva et al. (2002) destacam que para as condições de campo, os isolados de crescimento rápido, podem se estabelecer muito bem em reações de simbiose, ao superar a competição com outros organismos presentes no solo, bem como fatores abióticos como a acidez e as altas temperaturas. Estes isolados com crescimento rápido podem, portanto, apresentar potencial para inoculação em leguminosas em sistemas de produção agrícola nos solos ácidos da Amazônia, e assim, promoverem o melhor desenvolvimento e adaptação das espécies vegetais.

Observou-se que todos os isolados acidificaram o meio com pH 6,5, sendo verificada a alteração de cor do meio de verde para amarelo. Conforme Graham et al. (1994), a tolerância ao pH ácido em rizóbio depende da habilidade que eles possuem em manter o $\mathrm{pH}$ intracelular entre 7,2 e 7,5 quando o $\mathrm{pH}$ externo é ácido. Desse modo, pode-se inferir que os isolados do presente trabalho apresentam boa adaptação e mecanismos de sobrevivência aos solos ácidos da região. O tempo de crescimento pode também ser usado para a seleção, pois os isolados que apresentaram escores superiores a 3,06 em menor período de tempo pode ser mais tolerantes ao baixo $\mathrm{pH}$.

\section{Solubilização de fosfato de cálcio e fosfato de alumínio}

De um total de vinte e dois isolados, nove foram capazes de solubilizar o fosfato de cálcio (Tabela 5). A maioria dos isolados solubilizadores foram classificados como de baixa capacidade, enquanto que o isolado FCAN05a, a partir do sexto dia de avaliação, apresentou índices classificados como médio até o último dia de avaliação (Tabela 4). A respeito do tempo de solubilização, os que apresentaram solubilização, foram todos classificados como de solubilização precoce. Tais resultados demonstram a capacidade que estes microrganismos têm em solubilizar fosfatos, e deixam evidente a necessidade de mais estudos para avaliar suas potencialidades, tendo em vista futuras aplicações biotecnológicas. A capacidade de estirpes de rizóbio solubilizar o P-Ca está correlacionada com a diminuição do pH do meio pelos ácidos orgânicos produzidos a partir do metabolismo microbiano (MIKANOVA et al., 1999; MIKANOVA, 2000).

Tabela 4: Capacidade de solubilização de fosfato de cálcio dos isolados de rizóbio.

\begin{tabular}{|c|c|c|c|c|c|c|c|c|c|c|c|c|}
\hline \multirow{3}{*}{ Isolados } & \multicolumn{12}{|c|}{ Dias de avaliação } \\
\hline & \multicolumn{3}{|l|}{$3^{\circ}$} & \multicolumn{3}{|l|}{$9^{\circ}$} & \multicolumn{3}{|l|}{$12^{\circ}$} & \multicolumn{3}{|l|}{$15^{\circ}$} \\
\hline & $\varnothing c$ & $\varnothing \mathrm{H}$ & IS & $\varnothing c$ & $\varnothing \mathrm{H}$ & IS & $\varnothing c$ & $\varnothing \mathrm{H}$ & IS & $\varnothing c$ & $\varnothing \mathrm{H}$ & IS \\
\hline FCAN01a & 2,48 & 0,00 & 0,00 & 3,08 & 0,00 & 0,00 & 3,13 & 0,00 & 0,00 & 3,20 & 0,00 & 0,00 \\
\hline FCAN01b & 0,00 & 0,00 & 0,00 & 0,0 & 0,00 & 0,00 & 0,0 & 0,00 & 0,00 & 0,00 & 0,00 & 0,00 \\
\hline FCAN01c & 7,64 & 9,75 & 1,28 & 12,3 & 14,1 & 1,14 & 13,7 & 15,4 & 1,13 & 14,9 & 17,30 & 1,16 \\
\hline FCAN02b & 4,20 & 0,00 & 0,00 & 8,46 & 0,00 & 0,00 & 9,22 & 0,00 & 0,00 & 9,99 & 0,0 & 0,00 \\
\hline FCAN02c & 5,45 & 7,82 & 1,44 & 10,4 & 12,7 & 1,29 & 11,9 & 14,8 & 1,25 & 12,0 & 15,75 & 1,32 \\
\hline FCAN03a & 11,0 & 12,5 & 1,13 & 17,8 & 18,4 & 1,03 & 18,9 & 18,9 & 1,00 & 19,4 & 19,4 & 0,00 \\
\hline FCAN03b & 7,32 & 8,90 & 1,22 & 12,9 & 13,7 & 1,06 & 14,6 & 14,6 & 1,00 & 16,1 & 16,11 & 1,00 \\
\hline FCAN03c & 4,75 & 0,00 & 0,00 & 6,06 & 0,00 & 0,00 & 6,49 & 0,00 & 0,00 & 7,79 & 0,00 & 0,00 \\
\hline FCAN04a & 2,28 & 0,00 & 0,00 & 4,48 & 0,00 & 0,00 & 4,75 & 0,00 & 0,00 & 4,92 & 0,00 & 0,00 \\
\hline FCAN04b & 3,77 & 0,00 & 0,00 & 0,00 & 0,00 & 0,00 & 0,0 & 0,00 & 0,00 & 0,00 & 0,00 & 0,00 \\
\hline FCAN04c & 7,07 & 8,56 & 1,21 & 12,1 & 13,9 & 1,15 & 12,7 & 14,2 & 1,12 & 13,5 & 15,21 & 1,13 \\
\hline
\end{tabular}




\begin{tabular}{|c|c|c|c|c|c|c|c|c|c|c|c|c|}
\hline FCAN05a & 3,68 & 6,66 & 1,83 & 5,70 & 11,9 & 2,13 & 5,68 & 13,9 & 2,50 & 6,03 & 16,25 & 2,73 \\
\hline FCAN06a & 0,00 & 0,00 & 0,00 & 0,00 & 0,00 & 0,00 & 0,0 & 0,00 & 0,00 & 0,00 & 0,00 & 0,00 \\
\hline FCAN06b & 4,48 & 0,00 & 0,00 & 7,75 & 0,00 & 0,00 & 9,32 & 0,00 & 0,00 & 10,2 & 0,00 & 0,00 \\
\hline FCAN06c & 2,41 & 0,00 & 0,00 & 3,14 & 0,00 & 0,00 & 3,19 & 0,00 & 0,00 & 3,28 & 0,00 & 0,00 \\
\hline FCAN07a & 9,38 & 10,7 & 1,14 & 17,4 & 18,3 & 1,06 & 19,4 & 20,5 & 1,06 & 21,8 & 22,7 & 1,04 \\
\hline FCAN07b & 7,91 & 9,60 & 1,23 & 13,8 & 15,3 & 1,11 & 15,5 & 16,5 & 1,06 & 16,8 & 17,6 & 1,05 \\
\hline FCAN07c & 2,35 & 0,00 & 0,00 & 3,52 & 0,00 & 0,00 & 4,40 & 0,00 & 0,00 & 4,98 & 0,00 & 0,00 \\
\hline FCAN08a & 4,62 & 0,00 & 0,00 & 8,91 & 0,00 & 0,00 & 9,93 & 0,00 & 0,00 & 10,8 & 0,00 & 0,00 \\
\hline FCAN08b & 2,27 & 2,88 & 1,30 & 6,09 & 9,61 & 1,61 & 6,44 & 11,8 & 1,86 & 7,00 & 14,5 & 2,11 \\
\hline FCAN08c & 4,73 & 0,00 & 0,00 & 9,47 & 0,00 & 0,00 & 10,0 & 0,00 & 0,00 & 11,0 & 0,00 & 0,00 \\
\hline
\end{tabular}

Muitos trabalhos têm verificado a atividade de microrganismos isolados a partir de plantas presentes nos solos ácidos da Amazônia, como solubilizadores de fosfatos de cálcio, como o trabalho de Hara et al. (2007), no qual isolaram estirpes de rizóbios em solos ácidos no município de Rio Preto da Eva - AM, e em um total de 36 isolados, 26 foram capazes de solubilizar P-Ca, sendo que a maioria foi classificada como de solubilização média e crescimento precoce. Inácio et al. (2020) avaliou sete isolados de bactérias provenientes de rizosfera de plantas alimentícias não convencionais cultivadas na região metropolitana de Manaus, e detectou que todas foram capazes de solubilizar o fosfato de cálcio no terceiro dia de cultivo.

Os isolados não foram capazes de solubilizar fosfato de alumínio, tendo em vista que não foi observada a formação de halo de solubilização no experimento. Chagas Junior et al. (2010) observou que de um total de 26 isolados de rizóbios, 12 foram capazes de solubilizar fosfato de cálcio e 9 solubilizaram fosfato de alumínio. Era de se esperar maior proporção desses solubilizadores, em relação aos que solubilizam fosfato de cálcio, já que o fosfato de alumínio é a forma predominante nos solos da região (RAlJ, 1991).

\section{Capacidade de produzir AIA}

Dentre os isolados, 38\% foram capazes de produzir AIA (Tabela 6). Em relação aos níveis de produção de AIA por isolado, seis foram classificados como de nível médio de produção e dois como de baixo nível de produção, ou seja $75 \%$ apresentaram produção superior a $100 \mu \mathrm{g} \mathrm{mL}^{-1}$ na presença de triptofano (Tabela 5). A produção de AIA apresentada pelo isolados avaliados foi observada apenas na presença do triptofano, indicando que provavelmente para esses microrganismos, essa é a única rota metabólica de produção do referido fitohormônio.

Tabela 5: Isolados de rizóbio que produziram AIA.

\begin{tabular}{l|l|l}
\hline ISOLADOS & AIA $\left(\mu \mathbf{g ~ m}^{-1}\right)$ & Nível de produção de AIA* \\
\hline FCAN01a & 102,5187 & média \\
FCAN01b & 99,8520 & baixa \\
FCAN02b & 253,8520 & média \\
FCAN02c & 455,1853 & média \\
FCAN04c & 117,5187 & média \\
FCAN06c & 98,8520 & baixa \\
FCAN07b & 137,8520 & média \\
FCAN08a & 230,1853 & média \\
\hline Proporção (\%) & & Baixa (25\%) \\
\hline
\end{tabular}

* Classificação proposta por Chagas Junior et al. (2010).

Chagas Junior et al. (2010) identificaram a produção de AIA por rizóbios isolados de solos da Amazônia sem a adição de triptofano, no entanto, constatou-se o aumento da produção quando se 
acrescentou AIA ao meio e conforme foram aumentando-se suas concentrações, $52 \%$ dos isolados apresentaram aumento na produção de AIA. Desse modo, o aumento na concentração pode ser um meio de potencializar a produção dessa auxina pelos microrganismos.

Os isolados que apresentaram produção de AIA podem servir como potenciais inoculantes em espécies de interesse agrícola para promover o crescimento vegetal. De acordo com Hafeez et al. (2004) a produção de ácido indolacético é apontada como um dos fatores mais importantes para a promoção de crescimento em espécies vegetais. Schlindwein et al. (2008) destacam que essas bactérias podem inclusive atuar com promotoras de crescimento em espécies não leguminosas, ao qual o mecanismo de produção de AIA está envolvido. Ao avaliar a produção de AIA em meio de cultivo por rizóbios, Biswas et al. (2000) obtiveram resultados positivos para algumas estirpes de rizóbios testadas, ao qual se sugeriu como um mecanismo potencial pelo qual as bactérias regulam o crescimento das plantas. De acordo com Chagas Junior (2007) é provável que as auxinas de origem microbiana na rizosfera propiciem uma resposta fisiológica positiva nas plantas hospedeiras, desse modo, avaliar a produção de AIA "in vitro" pode proporcionar a seleção de rizóbios efetivos na produção dessa auxina.

\section{Formação de grupos de isolados com base nas características morfofisiológicas}

Observa-se a formação de 5 grupos distintos de rizóbios com $80 \%$ de grau de similaridade, evidenciando elevada diversidade morfofisiológica (Figura 3). Também se constata que alguns isolados da mesma planta apresentam diferenças marcantes quanto às suas características de acordo com a análise de cluster. Tal fato foi observado para os isolados obtidos napuerária-1, no qual o FCAN01a e FCAN01b apresentaram similaridade de aproximadamente 95\% das suas características, enquanto que o FCAN01c se encontra afastado desses isolados em termo de similaridade, se aproximando mais de isolados obtidos da mucuna preta (Figura 3).

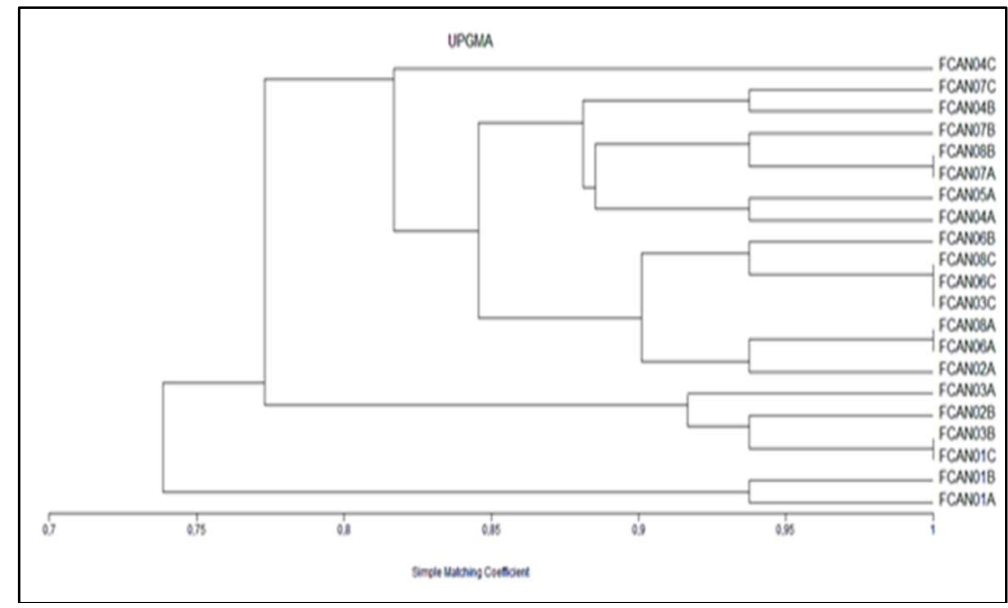

Figura 3: Índice de similaridade Simple Matching indicando a formação de grupos de isolados com base nas características morfofisiológicas.

Assim, foi identificado que isolados obtidos de uma espécie hospedeira, provavelmente poderão servir de inóculo para outra espécie, e provavelmente pertencem a grupos taxonômicos distintos. A caracterização morfológica de colônias bacterianas para a avaliação de diversidade serve como um 
complemento importante para as análises genéticas, uma vez que possibilita a construção de agrupamentos de indivíduos morfologicamente semelhantes (NAVROSKI et al., 2015).

\section{CONCLUSÕES}

Todos os isolados possuem plasticidade de crescimento na faixa de $\mathrm{pH}$ entre 4,5 e 6,0, e apresentaram tolerância à acidez. A tolerância à acidez não significou tolerância ao alumínio trocável, pois todos os isolados foram sensíveis a esse cátion.

Apenas nove isolados foram capazes de solubilizar o fosfato de cálcio, dos quais oito apresentaram baixa capacidade de solubilização e apenas o isolado FCAN05a apresentou índice médio até o último dia de avaliação. Todos foram classificados como de solubilização precoce. Os isolados não foram capazes de solubilizar o fosfato de alumínio.

Oito isolados foram capazes de produzir AIA, sendo que seis foram classificados como de nível médio de produção e dois como de baixo nível. Existe variabilidade morfofisiológica entre isolados da mesma planta e de uma mesma espécie.

\section{REFERÊNCIAS}

ANUAR, A. R.; SHAMSUDDEN, Z. H.; YAACOB, O.. Contribution of liming-N by nodulated groundnut for growth of maize on an acid soil. Soil Biol Biochem, v.27, n4-5, p.595601, 1995.

BERRAQUERO, F. R.; BAYA, A. M.; CORMENZANA, A. R.. Establecimiento de indices para el estúdio de la solubilizacion de fosfatos por bacterias del suelo. Ars Pharmacéutica, v.17, n.4, p.399-406, 1976.

BISWAS, J. C.; LADHA, J. K.; DAZZO, F. B.; YANNI, Y. G.; ROLFE, B. G.. Rhizobial inoculation influences seedling vigor and yield of rice. Agronomy Journal, v.92, n.5, p.880-886, 2000. DOI: https://dx.doi.org.10.2134/agroni2000.925880x

CAMPOS, M. C. C.; SANTOS, L. A. C.; SILVA, D. M. P.; MANTOVANELLI, B. C.; SOARES, M. D. R.. Caracterização física e química de terras pretas arqueológicas e de solos não antropogênicos na região de Manicoré, Amazonas. Revista Agro@mbiente, Roraiama, v.6, n.2, p.102-109, 2012. DOI: http://dx.doi.org/10.18227/1982-8470ragro.v6i2.682

CASSETARI, A. S.. Diversidade de bactérias diazotróficas nodulíferas na Mata Atlântica. Dissertação (Mestrado em Agronomia-Ciências do Solo e Nutrição de Plantas) Universidade de São Paulo, Piracicaba, 2010.

CHAGAS JUNIOR, A. F.. Características agronômicas e ecológicas de rizóbios isolados de solos ácidos e de baixa fertilidade na Amazônia. Tese (Doutorado em Biotecnologia) - Universidade Federal do Amazonas, Manaus, 2007.

CHAGAS JUNIOR, A. F.; OLIVEIRA, L. A.; OLIVEIRA, A. N.. Caracterização fenotípica de rizóbios nativos isolados de solos da Amazônia e eficiência simbiótica em feijão caupi. Acta Scientiarum. Agronomy, Maringá, v.32, n.1, p.161-169, 2010. DOI:

\section{https://dx.doi.org/10.4025/actasciagron.v32i1.900}

CHEN, W. M.; FARIA, S. M.; STRALIOTTO, R.; PITARD, R. M.; SIMOES-ARAUJO, J. L.; CHOU, J. F.; CHOU, Y. J.; BARRIOS, E.; PRESCOTT, A. R.; ELLIOTT, G. N.; SPRENT, J. I.; YOUNG, J. P. W.; JAMES, E. K.. Proof that Burkholderia strains form effective symbioses with legumes: a study of novel mimosanodulating strains from South America. Applied and Environmental Microbiology, v.71, n.11, p.7461-7471, 2005. DOI: http://doi.org/10.1128/AEM.71.11.7461-7471.2005

COSTA, E. M.; NOBREGA, R. S. A.; CARVALHO, F.; TROCHMANN, A.; FERREIRA, L. V. M.; MOREIRA, F. M. S. Promoção do crescimento vegetal e diversidade genética de bactérias isoladas de nódulos de feijão caupi. Pesquisa Agropecuária Brasileira, Brasília v.48, n.1, p.1275-84, 2013. DOI: http://dx.doi.org/10.1590/S0100-204X2013000900012

CUNHA, M. G.; SOUSA PINHEIRO, M.; GOUVEIA, F.; CAVALCANTE, S. C. S. M.; MARTINS, C. M.. Caracterização cultural e tolerância a ph extremos de rizóbios oriundos da região de baixo Acaraú no Ceará. Enciclopédia Biosfera, Jandaia, v.15, n.28, p.977-985, 2018. DOI: https://dx.doi.org/10.18677/EnciBio 2018B79

DEGEFU, T.; WOLDE-MESKEL, E.; ADEM, M.; FIKRE, A.; AMEDE, T.; OJIEWO, C.. Morphophysiological diversity of rhizobia nodulating pigeon pea (Cajanus cajan L. Millsp.) growing in Ethiopia. African Journal of Biotechnology, v.17, n.6, p.167-177, 2018. DOI: https://doi.org/10.5897/AJB2017.16338

EHRHARDT-BROCARDO, N. C. M.; STOCCO, P.; TRAMONTIN, A. L.; FILHO, L. C. I. O.; SANTOS, J. C. P.. Diversidade cultural, morfológica e genética de diazotróficos isolados de nódulos de Bracatinga. Revista Árvore, Viçosa, v.39, n.5, p.923-933, 2015. DOI: http://dx.doi.org/10.1590/0100$\underline{67622015000500015}$ 
FEITOZA, R. M.; SILVA, L. L.; PINHEIRO, M. S.; MARTINS, S. C. S.; MARTINS, C. M.. Diversidade fisiológica e bioquímica de estirpes de rizóbio do semiárido. Enciclopédia Biosfera, Goiânia, v.11, n.21, p.794-806, 2015.

FERNANDES, J. P. I.; LIMA, A. A. D.; PASSOS, S. R.; GAVA, C. A. T.; OLIVEIRA, P. J. D.; RUMJANEK, N. G.; XAVIER, G. R. Phenotypic diversity and amylolytic activity of fast growing rhizobia from pigeon pea (Cajanus cajan (L.) Millsp.) Brazilian Journal Microbiology, v.43, n.1, p.1604-1612, 2012. DOI: https://doi.org/10.1590/S151783822012000400045

FERREIRA, P. A. A.; BOMFETI, C. A.; SOARES, B. L.; MOREIRA, F. M. S.. Efficient nitrogen-fixing Rhizobium strains isolated from amazonian soils are highly tolerant to acidity and aluminium. World Journal Microbiol Biotechnol, v.28, n.1, p.1947-1959, 2012. DOI: https://doi.org/10.1007/s11274011-0997-7

FLIS, S. E.; GLENN, A. R.; DILWORTH, M. J.. The interaction between aluminum and root nodule bacteria. Soil Biology Biochemistry, v.25, n.4, p.403-417, 1993. DOI: https://doi.org/10.1016/0038-0717(93)90066-K

GIONGO, A.; AMBROSINI, A.; VARGAS, L. K.; FREIRE, J. R. J.; BODANESEZANETTINI, M. H.; PASSAGLIA, L. M. P.. Evaluation of genetic diversity of bradyrhizobia strains nodulating soybean [Glycinemax (L.) Merrill] isolated from South Brazilian fields. Apllied Soil Ecology, v.38, n.3, p.261-269, 2008. DOI: https://doi.org/10.1016/j.apsoil.2007.10.016

GRAHAM, P. H.; DRAEGER, K. J.; FERREY, M. L.; CONRAY, M. J.; HAMMER, B. E.; MARTINEZ, E.; AARONS, S. R.; QUINTINO, C.. Acid $\mathrm{pH}$ tolerance in strains of Rhizobium and initial studies on the basis for acid tolerance of Rhizobium tropici UMR 1899. Can. J. Microbiol., v.40, p.198-207,1994. DOI: http://doi.org/10.1139/m94-033

GUALTER, R. M. R.; BODDEY, R. M.; RUMJANEK, N. G.; FREITAS, A. C. R.; XAVIER, G. R.. Eficiência agronômica de estirpes de rizóbio em feijão-caupi cultivado na região da Pré-Amazônia maranhense. Pesq. Agropec. Bras., Brasília, v.46, n.3, p.303-308, 2011. DOI: http://dx.doi.org/10.1590/S0100-204X2011000300011

HAFEEZ, F. Y.; SAFDAR, M. E.; CHAUDHRY, A.; MALIK, K.. Rhizobialinoculation improves seedling emergence, nutrient uptake and growth of cotton. Australian Journal of Experimental Agriculture, Collingwood, v.44, n.6, p.617-622, 2004. DOI: 10.1071/EA03074

HAHN, L.; SÁ, E. L. S.; MACHADO, R. G.; SILVA, W. R.; OLDRA, S.; DAMASCENO, R. G.; SCHÖNHOFEN, A.. Growth promotion in maize with diazotrophic bacteria in succession with ryegrass and white clover. American and Eurasian Journal of Agriculture \& Environmental Science, v.14. n.1, p.11-16, 2014. DOI:

http://doi.org/10.5829/idosi.aejaes.2014.14.01.11893

HARA, F. A. S.; OLIVEIRA, L. A.. Características fisiológicas e ecológicas de isolados de rizóbio de solos ácidos de Iranduba, Amazonas. Pesquisa Agropecuária Brasileira, v.40, n.1, p.667-672, 2005. DOI: https://doi.org/10.1590/S0100$\underline{204 \times 2005000700007}$
HARA, F. A. S; OLIVEIRA, L. A.. Características fisiológicas e ecológicas de isolados rizóbios de solos oriundos de solos ácidos do município do Rio Preto da Eva, Amazonas. Revista Ciências Agrárias, Belém, n.48, p.55-70, 2007.

HARA, F. A. S.; OLIVEIRA, L. A.. Características fisiológicas e ecológicas de isolados de rizóbios oriundos de solos ácidos e álicos de Presidente Figueiredo, Amazonas. Acta Amazônica, Manaus, v.34, n.3, p.343-357, 2004. DOI: http://dx.doi.org/10.1590/S0044-59672004000300002

HARA, F. A. S.; OLIVEIRA, L. A.. Efectividade simbiótica de isolados de rizóbios em caupi (Vigna unguiculata L. walp) em latossolo ácido e álico na Amazônia. Brazilian Journal Development, Curitiba, v.5, n.12, 2019. DOI: http://doi.org/10.34117/bjdv5n12-017

HOMMA, A. K. O.; SANTOS, J. C.; SENA, A. L. S.; MENEZES, A. J. E. A.. Pequena produção na amazônia: conflitos e oportunidades, quais os caminhos?. Amazônia: Ci. \& Desenv., v.9, n.18, 2014.

HUNGRIA, M.; ARAÚJO, R. S.. Manual de métodos empregados em estudos de microbiologia agrícola. Brasília: EMBRAPA, 1994.

INÁCIO, A. C. F.; HARA, F. A. S. H.; VENDRUSCOLO, J.; NETO, P Q. C.; SOUZA, L. C. C.. Morphophysiological characterization of phosphate solubilizing bacteria from the rhizosphere of non-conventional food plants. Brazilian Journal Development, Curitiba, v.5, n.5, p.24567-2458, 2020. DOI: http://doi.org/10.34117/bjdv6n5-055

JARAMILLO, P. M. D.; GUIMARÃES, A. A.; FLORENTINO, L. A.; SILVA, K. B.; NÓBREGA, R. S. A.; MOREIRA, F. M. S.. Symbiotic nitrogen-fixing bacterial populations trapped from soils under agroforestry systems in the Western Amazon. Sci. Agric., v.70, n.6, p.397-404, 2013. DOI: http://dx.doi.org/10.1590/S0103-90162013000600004

JAISWAL, S. K.; NAAMALA, J.; DAKORA, F. D.. Nature and mechanisms of aluminium toxicity, tolerance and amelioration in symbiotic legumes and rhizobia. Biology and Fertility of Soils, v.54, p.309-318, 2018. DOI: https://doi.org/10.1007/s00374-018-1262-0

JESUS, E. D. C.; MOREIRA, F. M. S.; FLORENTINO, L. A.; RODRIGUES, M. I. D.; OLIVEIRA, M. S.. Leguminosae nodulating bacteria diversity from three different land use systems in Brazilian Western Amazon. Pesquisa Agropecuária Brasileira, v.40, n.8, p.769-776, 2005. DOI: https://doi.org/10.1590/S0100-204X2005000800006

KUMAWAT, D. M.; SHARMA, M. K.. Growth response of three indigenous Bradyrhizobium japonicum isolates against a few environmental factors. Int. J. Res. Pharm. Sci., v.5, n.2, p.7-11, 2015.

KOPITTKE, P. M.; MOORE, K. L.; LOMBI, E.; GIANONCELLI, A.; FERGUSON, B. J.; BLAMEY, F. P. C.; MENZIES, N. W.; NICHOLSON, T. M.; MCKENNA, B. A.; WANG, P.. Identification of the primary lesion of toxic aluminum in plant roots. Plant Physiol, v.167, n.1, p.1402-1411, 2015. DOI: https://doi.org/10.1104/pp.114.253229

LIMA, A. A.; FERNANDES JÚNIOR, P. I.; PASSOS, S. R.; PAULO, F. S.; NOSOLINE, S. M.; FARIA, S. M.; GUERRA, J. G. M.; 
RUMJANEK, N. G.; XAVIER, G. R.. Diversidade e capacidade simbiótica de rizóbios isolados de nódulos de Mucuna-Cinza e Mucuna-Anã. Revista Brasileira de Ciência do Solo, v.36, n.2, p.337-348 2012. DOI: https://dx.doi.org/10.1590/S010006832012000200003

MIKANOVA, O.. Study of the P-solubilizing microorganisms and their utilization for improving plant nutrition. Thesis (Dissertation) - Czech University of Agriculture Prague, Praga, 2000.

MIKANOVA, O.; KUBAT, J.. Practical use of P-solubilization a activity of Rhizobium species strains. RostlinnaVyroba, v.45, n.9, p.407409, 1999

MONTEIRO, P. H.; WINAGRASKI, E.; ANZALONE, R. A.; SILVA, F. B. DA; AUER, C. G.; HIGA, A. R.. Protocolo para crescimento de isolados bacterianos de nódulos de Acacia mearnsii e eficiência na solubilização de fosfato. Acta Iguazu, v.7, n.4, p.59-70, 2018. DOI:

https://doi.org/10.48075/actaiguaz.v7i4.19691

NAVROSKI, D.; SILVA, T. L.; SCHERER, A. J.; APPEL, R. J. C.; FAVETTA, A.; BARREIROS, M. A. B.; GRANGE, L.. Diversidade morfológica de rizobactérias obtidas de solos sob distintos manejos de cultivo da região oeste do Paraná. Revista Brasileira de Energias Renováveis, v.4, p.117-128, 2015. DOI: http://dx.doi.org/10.5380/rber.v4i2.42838

OGEGA, J. K.; WERE, B. A.; NEKESA, A. O.; OKALEBO, J. R.. Evaluating the effectiveness of different rhizobia strains and their effect on crop yields in acid soils of western Kenya. Turkish Journal of Agriculture - Food Science and Technology, v.6, n.2, p.195-198, 2018. DOI: https://doi.org/10.24925/turjaf.v6i2.195-198.1553

OSÓRIO FILHO, B. D.; GANO, K. A.; BINZ, A.; LIMA, R. F.; AGUILAR, L. M.; RAMIREZ, A.; CABALLERO-MELLADO, J.; SÁ, E. L. S.; GIONGO, A.. Rhizobia enhance growth in Rice plants under flooding conditions. American and Eurasian Journal of Agriculture \& Environmental Science, v.14, n.8, p.707718, 2014. DOI:

http://doi.org/10.5829/idosi.aejaes.2014.14.08.12377

OLIVEIRA, L. A.; MAGALHÃES, H. P.. Quantitative evaluation of acidity tolerance of root nodule bactéria. Revista de Microbiologia, v.30, n.1, p.203-208, 1999. DOI: https://doi.org/10.1590/S0001-37141999000300004

PADILLA, E. G.; RUIZ-DÍEZ, B. FAJARDO, S.; EICHLERLOEBERMANN, B.; SAMSON, R.; DAMME, P. V.; PERRINEWALKER, F. M.. Infection process and the interaction of rice roots with rhizobia. Journal of Experimental Botany, v.58, n.12, p.3343-3350, 2007. DOI: https://doi.org/10.1093/jxb/erm181

RAIJ, B. V.. Fertilidade do solo e adubação. Piracicaba: Agronômica Ceres, Associação Brasileira para a Pesquisa da
Potassa e do Fosfato, 1991.

ROSSUM, D. V.; MUYOTCHA, A.; HOOP, B. M.; VERSEVELD, H. W. V.; STOUTHOMER, A. H.; BOOGERD, F. C.. Soil acidity in relation to groundout-Bradyrhizobium symbiotic performance. Plant and Soil, v.163, n.1, p.165-175, 1994. DOI: https://doi.org/10.1016/S0734-9750(99)00014-2

SCHLINDWEIN, G.; VARGAS, L. K.; LISBOA, B. B.; AZAMBUJA, A. C.; GRANADA, C. E.; GABIATTI, N. C.; PRATES, F.; STUMPF, R. Influência da inoculação de rizóbios sobre a germinação e o vigor de plântulas de alface. Ciência Rural, v.38, n.3, 2008. DOI: https://doi.org/10.1590/S0103-84782008000300010

SILVA, A. F. S.; FREITAS A. D. S.; STAMFORD N. P.. Efeito da inoculação da soja (cv. Tropical) com rizóbios de crescimento rápido e lento em solo ácido submetido à calagem. Acta Scientiarum, v.24, n.5, p.1327-1333, 2002. DOI: https://doi.org/10.4025/actasciagron.v24i0.2371

STEFAN, A.; CAUWENBERGHE, J.; ROSU, C. M.; STEDEL, C.; LABROU, N. E.; FLEMETAKIS, E.; EFROSE, R. C.. Genetic diversity and structure of Rhizobium leguminosarum populations associated with clover plants are influenced by local environmental variables. Systematic and Applied Microbiology, v.41, n.3, p.251-259, 2018. DOI: https://doi.org/10.1016/j.syapm.2018.01.007

SYLVESTER-BRADLEY, R.; ASAKAWA, N.; LA TORRACA, S.; MAGALHÃES, F. M. M.; OLIVEIRA, L. A.; PEREIRA, R. M. Levantamento quantitativo de microrganismos solubilizadores de fosfato na rizosfera de gramíneas e leguminosas forrageiras na Amazônia. Acta Amazonica, v.2, n.1, p.15-22, 1982. DOI: http://dx.doi.org/10.1590/1809$\underline{43921982121015}$

WANI, S. P.; RUPELA, O. P.; LEE, K. K.. Sustainable agriculture in the semi-arid tropics through biological nitrogen fixation in grain legumes. Plant and Soil, v.147, n.1, p.19-49, 1995. DOI: https://doi.org/10.1007/BF00032240

YANNI, Y. G.; DAZZO, F. B.. Enhancement of rice production using endophytic strains of Rhizobium leguminosarum bv. trifolii in extensive field inoculation trial swithin the Egypt Nile Delta. Plant and Soil, v.336, p.129-142, 2010. DOI: https://doi.org/10.1007/s11104-010-0454-7

VIOLANTE, A.; COZZOLINO, V.; PERELOMOV, L.; CAPORALE, A. G.; PIGNA, M.. Mobility and bioavailability of heavy metals and metalloids in soil environments. J. Soil Sci Plant Nutr, v.10, p.268-29, 2010. DOI: http://dx.doi.org/10.4067/S0718$\underline{95162010000100005}$

ZIOŁA-FRANKOWSKA, A.; FRANKOWSKI, M.. Speciation analysis of alu- minium in plant parts of Betula pendula and in soil. J. Environ Sci., v.65, p.153-161, 2018. DOI: https://doi.org/10.1016/j.jes.2017.03.021

A CBPC - Companhia Brasileira de Produção Científica (CNPJ: 11.221.422/0001-03) detém os direitos materiais desta publicação. Os direitos referem-se à publicação do trabalho em qualquer parte do mundo incluindo os direitos às revacõs, expansões e disseminoc̃os da contribuiç̃o, bem como outros direitos subsidiários. Todos os trabalhos publicados eletronicamente poderão (astes preservam os direitos autorais, mas não têm permissão para a publicação da contribuição em outro meio, impresso ou digital, em português ou em tradução. 